\title{
ROUTINE CHEST ROENTGENOGRAPHY ON ADMISSION TO INTENSIVE CARE UNIT AFTER HEART OPERATIONS: IS IT OF ANY VALUE?
}

Walter O'Brien, FFARCSI ${ }^{a}$

Jacek M. Karski, MD ${ }^{\mathrm{a}}$

Davy Cheng, $\mathrm{MD}^{\mathrm{a}}$

Jo Carroll-Munro, $\mathrm{RN}^{\mathrm{a}}$

Charles Peniston, $\mathrm{MD}^{\mathrm{b}}$

Alan Sandler, MD ${ }^{\mathrm{a}}$
The need for routine immediate postoperative chest roentgenography after heart operations has recently been questioned. In this study we investigated the impact of routine postoperative chest roentgenography on treatment instituted in the cardiovascular intensive care unit immediately after heart operations done via median sternotomy. A total of 404 random patients admitted to the cardiovascular intensive care unit underwent clinical (positioning of endotracheal tube, nasogastric tube, and pulmonary artery catheter) and laboratory (oxygenation) assessment by a cardiovascular intensive care unit physician according to a strict protocol. After clinical assessment, chest roentgenography was done for all admitted patients and the findings reviewed by the same physician. Pathologic conditions noted were recorded on the study form together with any required treatment. Eighteen patients $(4.5 \%)$ out of 404 required intervention because of abnormalities detected by the chest $x$-ray film but not predicted by the initial physical and laboratory assessment. None of the pathologic conditions detected was life threatening. We conclude that chest roentgenography done on admission to the cardiovascular intensive care unit should be done only if clinical and laboratory assessment indicate the possibility of underlying pathologic conditions that can only be confirmed or diagnosed by chest roentgenography. (J Thorac Cardiovasc Surg 1997;113:130-3)
$\mathrm{R}$ outine immediate postoperative chest roentgenography is still obligatory in many institutions after heart operations. Its proponents indicate that intravascular line placement; the positioning of the endotracheal, nasogastric, and chest tubes; and possible pathologic conditions in the lungs after heart operations warrant performance of chest roentgenography in all patients after admission to the intensive care unit (ICU) after cardiac operation. ${ }^{1,2}$

With the recent trend of fast tracking patients having cardiac operations with short-term postoperative sedation and artificial lung ventilation followed by early extubation of the trachea, the need for routine nonselective chest roentgenography on admission to the ICU after cardiac operations has been ques-

From the Department of Anesthesia ${ }^{a}$ and the Division of Cardiovascular Surgery ${ }^{\mathrm{b}}$ of The Toronto Hospital, University of Toronto, Toronto, Ontario, Canada.

Received for publication April 15, 1996; revisions requested June 11, 1996; revisions received July 11, 1996; accepted for publication July 19, 1996.

Address for reprints: Jacek M. Karski, MD, Department of Anesthesia, The Toronto Hospital, 200 Elizabeth St., Toronto, Ontario, Canada, M5G 2 C4.

Copyright (c) 1997 by Mosby-Year Book, Inc.

$0022-5223 / 97 \$ 5.00+0 \quad \mathbf{1 2} / \mathbf{1} / \mathbf{7 6 8 3 0}$ tioned. ${ }^{3}$ Cardiac operation done via median sternotomy facilitates inspection of the mediastinum and allows for assessment of lung movement. Recently in the literature it has been suggested that routine postoperative chest roentgenography may be omitted., 5

Routine preoperative chest roentgenography has already been shown to be of little use in patient treatment. ${ }^{6}$ Even in emergency medical admissions the role of nonselective chest roentgenographic examination has been questioned. The risk of carcinogenesis from exposure to radiation during chest roentgenography is cumulative and although generally considered trivial for each individual exposure, the risk may be more substantive than previously accepted. ${ }^{7}$

The questionable clinical value of immediate postoperative chest roentgenography and its cost, both financially and in terms of radiation exposure, prompted us to study whether it is really necessary to continue the practice of performing chest roentgenography on every patient after fast track cardiac operation. $^{8}$

\section{Methods}

During a 6-month period we studied 423 random patients (when an anesthesia fellow was on call for the cardiovascular ICU) admitted to the cardiovascular 
Table 1. Demographics and type of operation

\begin{tabular}{lc} 
Age (yr) & $61 \pm 13$ \\
Male $(\%)$ & 71 \\
Female $(\%)$ & 29 \\
Repeat operation $(\%)$ & 22 \\
CABG $(\%)$ & 72 \\
Valve operation $(\%)$ & 16 \\
CABG + valve operation $(\%)$ & 5 \\
Other operation $(\%)$ & 7 \\
\hline
\end{tabular}

Age values given as mean plus or minus the standard deviation. $C A B G$, Coronary artery bypass grafting.

ICU after heart operation done via median sternotomy. All patients were admitted to the cardiovascular ICU sedated, the trachea intubated, and lungs artificially ventilated with an inspiratory oxygen concentration of a minimum of 0.6 . Sedation after arrival to the cardiovascular ICU was continued according to our standard practice and patients were extubated within 4 to 6 hours after admission.

On admission to the cardiovascular ICU patients underwent clinical and laboratory assessment by cardiovascular ICU fellows or staff physicians. The position of the endotracheal tube was assessed by auscultation of air entry to both lungs. Adequacy of artificial lung ventilation was assessed by continuous measurement of hemoglobin oxygen saturation by pulse oximetry and by arterial blood gas analysis done immediately on admission to the cardiovascular ICU. The position of the pulmonary artery (PA) catheter was assessed by evaluation of the waveform of the PA pressure and the ability to wedge the pulmonary catheter. Nasogastric tube position was assessed by suctioning of gastric fluid or by insufflating the nasogastric tube with air while listening over the stomach with a stethoscope for characteristic sounds. Hemodynamic stability of the cardiovascular system was present when systemic blood pressure was higher than $90 \mathrm{~mm} \mathrm{Hg}$ and the cardiac index exceeded $2 \mathrm{~L} / \mathrm{m}^{2}$ per minute. Excessive bleeding was diagnosed if blood loss exceeded $400 \mathrm{ml}$ in the first hour after admission to the ICU.

On the basis of this evaluation the physician completed a simple questionnaire and was asked to predict whether any pathologic findings were expected on routine supine portable chest roentgenography.

After clinical assessment, chest roentgenography was done on all admitted patients as is our routine standard of care and the film was reviewed by the same physician who had done the clinical assessment of the patient. Pathologic findings noted by the involved clinician were recorded on the study form together with any required treatment. As is routine the roentgenographic results were reported on the following day by a staff radiologist. Routine demographic data related to patients and the type of surgical procedure done were also collected.

Four hundred twenty-three patients underwent evaluation and data analysis was done on 404 patients (19 patients had unfinished data collection). Data were entered into a database created in SYSTAT 5.03 (SYSTAT, Inc., Evanston, Ill.).
Table II. Chest $x$-ray film pulmonary abnormalities as reported by evaluating clinician

\begin{tabular}{cccc}
\hline$X$-ray film findings & \multicolumn{1}{c}{ Right } & Left & Bilateral \\
\hline Collapse & $4(1 \%)$ & $13(3.2 \%)$ & $1(0.25 \%)$ \\
Effusion & $3(0.75 \%)$ & $3(0.75 \%)$ & 0 \\
Edema & & & $13(3.2 \%)$ \\
\hline
\end{tabular}

\section{Results}

Patient demographics are presented in Table I. Eighteen patients $(4.5 \%)$ out of 404 required intervention because of abnormalities discovered by chest roentgenography but not predicted by the initial physical and laboratory assessment. The incidence of significant pulmonary pathologic findings recorded by the clinician assessing the chest roentgenograms is presented in Table II. The common abnormalities reported included left lower lobe collapse, pulmonary edema, and pleural effusion.

Five patients $(1 \%)$ had the endotracheal tube repositioned because on the $\mathrm{x}$-ray film the tubes were judged too close to the carina (Table III). All of these cases were clinically unsuspected because all patients had normal air entry and arterial oxygen tension $\left(\mathrm{PaO}_{2}\right)$ greater than $90 \mathrm{~mm} \mathrm{Hg}$. PA catheters were distally placed in 25 patients, of which cases 17 were clinically suspected and corrected before chest roentgenography. Unexpected distal positioning of the PA catheter was evident by chest roentgenography in $8(2.0 \%)$ of 399 patients. In all these patients the PA pressure waveform had been clinically assessed as within normal limits and in all the PA catheter had been wedged without any problem.

One patient had pulmonary edema necessitating treatment with diuretics that was discovered by chest roentgenography after normal findings of arterial blood gas values and physical examination of the chest.

Of note, at admission to the cardiovascular ICU 29 of 404 patients had a $\mathrm{PaO}_{2}$ value less than $90 \mathrm{~mm}$ $\mathrm{Hg}$ despite artificial ventilation of the lungs with an inspiratory oxygen concentration of about 0.6. Pulmonary pathologic conditions were present in 17 of these patients as detailed in Table IV. No patient had pneumothorax.

\section{Discussion}

Results of our study clearly indicate that there is no need to perform routine chest roentgenography on patient admission to the cardiovascular ICU after heart operations. Chest roentgenography 
Table III. Abnormalities of endotracheal, nasogastric tube, and PA catheter placement

\begin{tabular}{llcc}
\hline & Assessment & Abnormal & Total \\
\hline Endotracheal tube & Clinical & $7(1.7 \%)$ & 402 \\
& X-ray film & $5(1.25 \%)$ & 402 \\
Nasogastric tube & Clinical & $21(6 \%)$ & 346 \\
\multirow{4}{*}{ PA catheter } & X-ray film & $4(1 \%)$ & 346 \\
& Clinical & $17(4 \%)$ & 399 \\
& X-ray film & $8(2 \%)$ & 399 \\
\hline
\end{tabular}

$P A$, Pulmonary artery.

should be done in a selective fashion after clinical and laboratory evaluation of the patient's condition. Although $4.5 \%$ of the underlying pathologic conditions were missed by physical assessment none of these was life threatening. Routine chest roentgenography increases the cost of care for patients undergoing cardiac operation and expose them, as well as personnel in the ICU, to radiation without clear benefit to patient treatment.

This supports the conclusions of Hornick and associates ${ }^{4}$ who reported a series of 100 consecutive adult patients after cardiac operation. They concluded that the policy of obtaining routine postoperative chest radiographs in the absence of a specific clinical indication provides virtually no additional diagnostic yield. In a further study, Stevens and associates $^{5}$ reported that only 1 out of 110 patients after cardiac operation underwent therapeutic action solely on the basis of findings of the routine immediate postoperative chest $x$-ray film and concluded that in the absence of abnormal clinical findings routine immediate postoperative chest roentgenography is of little value.

In our series we have reported a much lower prevalence of pulmonary pathologic findings than reported in other series that reviewed chest roentgenographic changes after cardiac operation. The most likely explanation for this discrepancy is that the roentgenographic changes reported here were reported by clinicians who may regard minor degrees of pulmonary pathologic conditions as a normal finding after cardiac operation. It is well recognized that patients after cardiac operation have a high prevalence of pulmonary pathologic conditions, but it would be false to argue that chest roentgenography should be done to confirm the presence of an abnormality or its extent unless it is causing a problem and something specific can be done to improve the situation. Furthermore it should be stressed that it is the patient who is treated, not the $x$-ray film.
Table IV. Pulmonary pathologic findings in patients having $\mathrm{PaO}_{2}$ values less than $90 \mathrm{~mm} \mathrm{Hg}$ on admission to cardiovascular ICU

\begin{tabular}{lcc} 
& No. & $\%$ \\
\hline LLL collapsed & 5 & 17.2 \\
RLL collapsed & 3 & 10.3 \\
Pulmonary edema & 8 & 27.6 \\
Pleural effusion & 1 & 3.5 \\
\hline
\end{tabular}

$L L L$, Left lower lobe of the lung; $R L L$, right lower lobe of the lung.

In our unit, as in many other units, taking the portable chest roentgenogram involves lifting the patient's thorax from the bed to allow for positioning of the X-ray plate. In our series this resulted in dislodgement of the PA catheter into the right ventricle on three occasions, and it is a potential threat to the patient's hemodynamic stability.

It is interesting that 69 patients $(17 \%)$ out of 404 were expected to have abnormalities on the chest $\mathrm{x}$-ray film after clinical and laboratory assessment but only 42 patients (10.3\%) out of 404 actually had abnormalities on the films, which gives a $7 \%$ error for clinical and laboratory assessment as an indication for chest roentgenography.

If an institution changes from a policy of routine immediate postoperative chest roentgenography to a policy based on ordering roentgenography on clinical grounds, clear guidelines should be implemented to ensure that the standard of patient care is maintained. The attending anesthetist and surgeon involved with the patient should confirm that there were no clinical problems with line or endotracheal tube placement and that there were no surgical indications that would warrant immediate chest roentgenography. Physical examination should include assessment of endotracheal and nasogastric tube placement. Adequacy of oxygenation should be assessed by continuous oximetry or intermittent measurements of $\mathrm{PaO}_{2}$ and the accuracy of the PA catheter placement should be assessed by inspection of both the waveform and the depth of insertion. Chest roentgenography should be done when an intraaortic balloon has been inserted to confirm its position.

In our series $2 \%$ of the patients had clinically unsuspected distal positioning of the PA catheter. This situation may represent an increased risk for PA rupture if attempts are made to wedge the PA catheter. In our series no such complication occurred but until future studies are done it would be prudent to perform chest roentgenography before one attempts to wedge the PA catheter. 
Our data clearly indicate that we can reduce the number of chest $x$-ray films taken in our institution by $83 \%(1600)$ yearly with a savings of approximately $\$ 48,000$ Canadian (allowing for an average direct institutional cost of $\$ 30$ Canadian per film).

Chest roentgenography on admission to the cardiovascular ICU should be done only if clinical and laboratory assessments indicate the possibility of underlying pathologic conditions that can only be confirmed or diagnosed by chest roentgenography. On the basis of the results of our study and studies reported previously we have changed our practice from routine chest roentgenography done for every patient entering the cardiovascular ICU after heart operation to selective, clinically indicated chest roentgenography.

\section{REFERENCES}

1. Goodman LR. Postoperative chest radiograph: II-alterations after major intrathoracic surgery. Am J Roentgenol 1980;134: 803-13.
2. Wieneecr-Kronish JP. Postoperative pleural and pulmonary abnormalities in patients undergoing coronary bypass grafts [Editorial]. Chest 1992;102:1313-4.

3. Westaby S, Pillai R, Parry A, et al. Does modern cardiac surgery require conventional intensive care? Eur J Cardiothorac Surg 1993;7:313-8.

4. Hornick PI, Harris P, Cousins C, Taylor KM, Keogh BE. Assessment of the value of the immediate postoperative chest radiograph after cardiac operation. Ann Thorac Surg 1995;59: 1150-4.

5. Stevens JJ, Booth JV, Little J, et al. The value of immediate postoperative chest radiograph in adult cardiac surgery (abstract). Br J Anaesth 1995;74:A110.

6. Archer C, Levy A, McGregor M. Value of routine preoperative chest x-rays: a meta analysis. Can J Anaesth 1993;40: 1022-7.

7. Robin E, Burke C. Routine chest x-ray examinations. Chest 1986;2:258-62.

8. Cheng DCH, Karski J, Peniston C, Asokumar B, Raveendran $\mathrm{G}$, Carroll J, et al. Morbidity outcome in early versus conventional tracheal extubation after coronary artery bypass grafting: a prospective randomized controlled trial, J Thorac Cardiovasc Surg 1996;112:755-64.

\section{Availability of Journal back issues}

As a service to our subscribers, copies of back issues of The Journal of Thoracic and Cardiovascular Surgery for the preceding 5 years are maintained and are available for purchase from Mosby at a cost of $\$ 15.00$ per issue until inventory is depleted. The following quantity discounts are available: $25 \%$ off on quantities of 12 to 23 , and one third off on quantities of 24 or more. Please write to Mosby-Year Book, Inc., Subscription Services, 11830 Westline Industrial Drive, St. Louis MO 63146-3318, or call 800-453-4351 or 314-453-4351 for information on availability of particular issues. If unavailable from the publisher, photocopies of complete issues may be purchased from UMI, 300 N. Zeeb Rd., Ann Arbor, MI 48106, 313-761-4700. 